\title{
Factors Affecting Household Food Security in Gumay Woreda of Jimma Zone of Oromia, Ethiopia
}

\author{
Debeli Chala Biyena*, Hailu Wondu, Befkadu Mewded \\ Forest and Range Land Directorate, Ethiopian Biodiversity Institute, Addis Ababa, Ethiopia
}

Email address:

cchalabiyana@gmail.com (D. C. Biyena)

${ }^{*}$ Corresponding author

\section{To cite this article:}

Debeli Chala Biyena, Hailu Wondu, Befkadu Mewded. Factors Affecting Household Food Security in Gumay Woreda of Jimma Zone of Oromia, Ethiopia. International Journal of Economic Behavior and Organization. Vol. 9, No. 3, 2021, pp. 85-93.

doi: $10.11648 /$ j.ijebo.20210903.16

Received: July 17, 2021; Accepted: August 12, 2021; Published: August 24, 2021

\begin{abstract}
This study is focused on factors affecting household food security in Gumay woreda, Jimma zone, Oromia regional state, Ethiopia. The problem of food security is one the challenges that farmers in the study area deal with. The general objective of the study is to assess factors affecting households to food security in the study area. Both secondary and primary data were used for the study. The study was based on the survey of a total of 72 households randomly selected using three-stage sampling techniques; purposive sampling, stratified sampling and systematic sampling. Analytical tools used include descriptive statistics and econometrics model. The total household expenditure per adult equivalent is taken to compute proxy indicator of food security. The findings revealed that about $72.22 \%$ and $22.78 \%$ of farmers in the woreda were food secure and food insecure respectively. Logistic model analysis result showed age, cultivated land, improved seed, fertilizer and tropical livestock units were the major factors positively and significantly influence food security status. The findings suggest the following set of policy recommendation. Identifying and understanding factors that are responsible for household's food security status and its determinants is important to combat food security problems at the household level. The study findings suggest that in selecting priority intervention areas, the food security strategy should consider statistically significant variables as the most important areas.
\end{abstract}

Keywords: Food Security, Logit Model, Expenditure Per Adult Equivalent, Gumay Woreda

\section{Introduction}

The world population has grown steadily, with most people now living in urban areas. Technology has evolved at a dizzying pace, while the economy has become increasingly interconnected and globalized. Many countries, however, have not witnessed sustained growth as part of this new economy. The world economy as a whole is not growing as much as expected. Conflict and instability have increased and become more intractable, spurring greater population dislocation. Climate change and increasing climate inconsistency and extremes are affecting agricultural productivity, food production and natural resources, with impacts on food systems and rural livelihoods, including a decline in the number of farmers. All of this has led to major shifts in the way in which food is produced, distributed and consumed worldwide - and to new food security, nutrition and health challenges. Recent editions of the report revealed that the decline in famine the world had enjoyed for over a decade was at an end, and that hunger was again on the rise. The global level of the prevalence of undernourishment has stabilized; however, the absolute number of undernourished people continues to increase, although slowly. More than 820 million people in the world are still starving today, underscoring the immense challenge of achieving the Zero Hunger target by 2030. Hunger is rising in almost all sub regions of Africa and, to a lesser extent, in Latin America and Western Asia. Food insecurity is still a major global concern as 2 billion people in the world experience moderate or severe food insecurity. People who are moderately food insecure lack regular access to nutritious and sufficient food, putting them at greater risk of malnutrition and poor health.[7].

In 2017, FAO [8] reported that the prevalence of hunger was on the rise in Africa, after many years of decline. The latest data, presented in this years' Regional Overview, 
confirms that this trend continues, with Central and Western Africa faring the worst. Today, a fifth of Africans are undernourished, representing a staggering 257 million individuals. The main causes deteriorating trend in Africa is due to difficult global economic and worsening environmental conditions and, in many countries, conflict and climate unpredictability and extremes, sometimes combined. Economic growth reduced in 2016 due to feeble product prices, in particular for oil and minerals. [9].

Many factors are contributing to trap Ethiopia in the current state of food insecurity and poverty. These include production fluctuations, low non-farm employment, low income, regional fragmentation of markets, high rate of natural degradation, low level of farm technology, high level of illiteracy and inadequate quality of basic education, poor health and sanitation, high population growth, poor governance and inter-state, intra-state military conflicts and wars. These factors impede the achievement of food security and sustainable economic development. It has one of the lowest per capita incomes in the world but rapidly reduced to $29.6 \%$ of the population below the poverty line [9].

Oromia region also characterized by sever environmental degradation, high population pressure and over cultivation of the central highland areas. This combined with massive deforestation and destruction of natural vegetation cover has resulted in serious erosion and then low agricultural production. Thus, the region is affected by cyclical drought and food insecurity is the major problem facing the region. Food aid has been used to fill the food demand gap of the people. In the region food aid has been used to enhance the level of food supplies and protect the income of victims of drought and famine [6]. The empirical study on food insecurity, school absenteeism and educational attainment of adolescents in Jimma Zone Southwest Ethiopia, found that food insecurity had negative impact on educational attainment of adolescents [15]. There was no study undertaken on farmer food security in Gumay woreda yet. So, this study was a corner stone for other researchers who want to study the household food security in Gumay woreda.

\section{Statement of the Problem}

The majority of the severest food crises after the second half of the 20th century were caused by a combination of several factors. The most common causes of food insecurity in African and other third world countries were; drought and other extreme weather events, pests, livestock diseases and other agricultural problems, climate change, military conflicts, lack of emergency plans, corruption and political instability, cash crops dependence, aids and rapid population growth [3].

According to the FAO [10], 41\% of the Ethiopian population lives below the poverty line and more than 31 million people are undernourished. However, the latest undernourishment numbers show a positive trend (1990-92: $71 \%$ of the population; $1995-97: 64 \%$; 2000-02: $50 \%$; 200406: 44\%). The concentrations of food insecurity and malnutrition are prevalent in rural areas with a population of six to seven million chronically food insecure and up to 13 million seasonally food insecure.

Different studies are suggested different reasons for the increasing trend of farmer food insecurity in the country. One of the major factors that have contributed to food insecurity in Ethiopia was land degradation. At least 1.5 billion tons of top soil has been washed away each year. On top of this, recurrent drought and war-torn economies of the country also aggravate the problem and led to massive food grain deficit and farmer food insecurity [2].

Berhanu [4] identified different factors that cause food insecurity. These are worsening of food production capacity (due to drought and land degradation), population pressure and instability and armed conflict. [12], using binary logit model indicated that family size and age of the household head have positive and significant effect on farmer food insecurity; whereas, educational status of the household head, asset possession, credit access and access to employment have negative effect.

The above empirical findings [12] showed dissimilar variables statistically significance that influences household food security either positively or negatively. But the limitations of the above studies where they did not inspect statistically the influence of the following variables such as cultivated land, improved seed, fertilizer and tropical livestock unit on the status of farmer food security. This study fills the gap of the above studies by examining statistically the influences of cultivated land, improved seed, fertilizer and tropical livestock unit on household food security in Jimma zone especially in Gumay woreda and giving possible policy recommendation to curb the problem of food insecurity in the study area.

\section{Methodology of the Study}

The study emphasized on factors affecting household's food security in GumayWoreda, Jimma zone of Oromia Regional State, Ethiopia. Gumay woreda is found in Jimma Zone of Oromia Regional State, and located at $415 \mathrm{~km}$ South West of Finfine and $69 \mathrm{~km}$ from zonal town. Geographically, it is located at an altitude of $2,370 \mathrm{~m}$ above sea level. The annual rainfall ranges from $1,400-1,600 \mathrm{~mm}$ and the mean annual temperature is $20-25^{\circ} \mathrm{C}$. The woreda was established in 1996 and has a total population of 77,680 of which $51.6 \%$ are male and $48.4 \%$ are female and 8,961 of households in 14 administrative kebeles. Agriculture is the main economic activity and the common agricultural products are coffee, maize, teff, sorghum and others. The woreda has one health center, fourteen first cycle primary schools (grade 1-4), eight second cycle primary schools (Grade 5-8), three high schools and one prepatory school. The woreda is mostly inhabited by the Oromo's and some other ethnic groups. The dominant language spoken in the woreda is Afan Oromo and the rest is Amharic. Muslim is the dominant religion in the woreda and the remaining are Protestant, Orthodox and Waqeffata.

Both qualitative and quantitative data were used in this 
study. In this study primary data was collected from the farmers in study area (Gumay woreda). Information on the demographic and socio-economic condition of the farmer was collected through structured questionnaires. The structured questionnaires were inquiries about demographic and socio-economic aspects such as sex, age, family size, education, cultivated land, improved seed, fertilizer, income and tropical livestock unit. Relevant data collected from the secondary sources were supplement to primary information. The secondary sources from published and unpublished documents were extensively reviewed.

A multi-stage sampling technique was employed to get the required primary data. At first, Gumay woreda was selected purposively among 18 woredas of Jimma zone because food insecurity highly prevails in the woreda. Second, stratified sampling was employed to categorize households in to three strata based on types of crops they produce.

With proportionate stratified sampling 72 representative households in the study area was allocated to three strata and to each kebeles based on the number of farmers existed in each stratum and kebeles respectively. Then 22 households were selected from strata I, 12 households from strata II, and 38 households were from strata III were selected. Third, systematic sampling was employed to select representative households from each kebeles. The first household was selected by lottery method and then the rest survey points selected by interval.

In this study, the total farmer expenditure per adult equivalent (AE) is taken to compute proxy indicator of food security. The reasons for using total farmer expenditure rather than income were; First consumers normally understate their incomes than their total expenditure. Second reason is based on a theoretical argument. As it may be evoked from the theoretical framework of economic theory, traditional consumer maximizes his total utility subject to his budget constraint that is his total expenditure. So, if expenditure is assumed to be directly consumed, it contributes to utility directly while income contributes indirectly.

The logit model is designed to analyze qualitative data reflecting a choice between two alternatives, which in this case are the food secure and food insecure. The choice of the logit model is premised on the fact that ordinary least squares assume a continuous dependent variable while in the case of food security the response is a binomial process taking the value 1 for food secure and 0 for food insecure. The parameters of this model were be estimated by using the maximum likelihood estimation rather than the movement estimation in which OLS regression technique rely on. The logit method gives parameter estimates that are asymptotically efficient, and consistent. Indeed, the logit approach is known to produce statistically sound results [11]. Probability of being food secure is specified as the value of the cumulative distribution function which is specified as function of the explanatory variables.

The cumulative logistic probability model can be econometrically specified as:

$$
\mathrm{P}_{\mathrm{i}}=\mathrm{F}\left(\mathrm{Z}_{\mathrm{i}}\right)=\mathrm{F}\left(\alpha+\beta_{\mathrm{i}} \mathrm{X}_{\mathrm{i}}\right)=\frac{1}{1+e^{-z i}}
$$

Where, $\mathrm{Pi}$ is the probability that an individual is being food secure given Xi

$\mathrm{Xi}$ represents the ith explanatory variables

$\alpha i \& \beta i$ are regression parameters to be estimated

$\mathrm{e}$ is the base of the natural logarithm.

For the case of interpretation of the coefficients a logistic model could be written in terms of the odds and log off odd. The odd ratio is the ratio of the probability that an individual or household would be food secure $(\mathrm{Pi})$ to the probability of a household would not be food secure (1-P). That is:

$$
\frac{\mathrm{pi}}{1-\mathrm{Pi}}=e^{z i}
$$

and taking the natural logarithm of equation (2) yields:

$$
\operatorname{Ln}\left(\frac{\mathrm{Pi}}{1-\mathrm{Pi}}\right)=Z i=\alpha+\beta 1 \mathrm{x} 1+\beta 2 \times 2+--+\beta \mathrm{nXn}
$$

If the disturbance term Ui is taken into account, the logit model becomes:

$$
\mathrm{Zi}=\alpha+\sum_{\mathrm{i}=0}^{\mathrm{n}} \beta_{\mathrm{i}} \mathrm{X}_{\mathrm{i}}+\mathrm{ui}-
$$

The parameters of the model $\alpha$ and $\beta$ can be estimated using the maximum likelihood (ML) method.

\section{Result and Discussion}

In this chapter factors affecting farmer food security are empirically analyzed. The descriptive analyses were graph presentation, tabulation of mean, percentage, standard deviation, and t-test. In the econometric analyses were $\chi^{2}$ test, odds ratio, correlation coefficient between different factors that affect households' food security in the study areas and logit regression model results are presented.

\subsection{Description of Socioeconomic Characteristics}

As the above table 1 shows that from the total sample households, $72.22 \%$ are food secure while $27.78 \%$ are food insecure households.

Age distribution of the households

The average age of the sample households in the study area was about 46.16 years. The minimum age was 25 whereas the maximum was 69 years. The majority of the sample households, $47.22 \%$ were between $53-69$ years where $41.67 \%$ of them were food secure and $5.56 \%$ of them were food insecure. The mean age of food secure households was 44.25 years and for food insecure households was 51 years. The mean age difference between food secure and food insecure households at $\mathrm{t}$-value $=6.9$ was statistically significance at $5 \%$ probability level (Table 2 ). This finding showed that as household age increased probability of the households being to be food secure increased because the household get more experience in farming that maximize his agricultural production and awareness of holding more accumulated assets (wealth) higher than younger households. 
Table 1. Distribution of sample households by expenditure range per AE.

\begin{tabular}{lllllll}
\hline \multirow{2}{*}{ Expenditure of households in birr } & \multicolumn{2}{l}{ Food secure households } & \multicolumn{2}{l}{ Food insecure households } & Total & \% \\
\cline { 2 - 7 } & No. & \% & No. & \% & No. & \% \\
\hline $2100-4200$ & - & - & 20 & 27.78 & 20 & 27.78 \\
$4201-7,600$ & 3 & 4.17 & - & - & 3 & 4.17 \\
$7,601-11,400$ & 12 & 16.57 & - & - & 12 & 16.67 \\
$11,401-15,200$ & 23 & 31.94 & - & - & 23 & 31.94 \\
$15,201-19,000$ & 7 & 9.72 & - & - & 4 & 9.72 \\
$1901-22800$ & 4 & 5.56 & - & - & 3 & 5.56 \\
$>22800$ & 3 & 4.17 & - & - & 3 & 4.17 \\
\hline
\end{tabular}

Own computation, 2016/2017.

Table 2. Age distribution of the households.

\begin{tabular}{|c|c|c|c|c|c|c|}
\hline \multirow{2}{*}{ Age of households } & \multicolumn{2}{|c|}{ Food secure, $N=52$} & \multicolumn{2}{|c|}{ Food insecure, $N=20$} & \multicolumn{2}{|c|}{ Total, $N=72$} \\
\hline & Number & Percent & Number & Percent & Number & Percent \\
\hline $25-37$ & 6 & 8.33 & 10 & 13.89 & 16 & 22.22 \\
\hline $38-52$ & 16 & 22.22 & 6 & 8.33 & 22 & 30.56 \\
\hline $53-69$ & 30 & 41.67 & 4 & 5.56 & 34 & 47.22 \\
\hline Total & 52 & 72.22 & 20 & 27.78 & 72 & 100 \\
\hline \multicolumn{7}{|c|}{ Mean: 44.2551 .1546 .17} \\
\hline \multicolumn{7}{|c|}{ St. dev: 8.6211 .599 .95} \\
\hline $\mathrm{t}$-value $=6.9, \mathrm{P}<0.0$ & & & & & & \\
\hline
\end{tabular}

Own computation, 2016/2017 Significant at 5\%

Cultivated land distribution of the households

The mean size of cultivated land in the study areas was 6.83 hectares. Majority of households, 59.72\% owned cultivated land ranging between 6-10 hectares. The mean cultivated land for food secure households was 7.72 hectares and for food insecure households was 4.53 hectares. The mean difference of cultivated land holding between the two groups at t-value $=3.396$ was statistically significance at $5 \%$ probability level. (Table 3 ). This implies in the study area, households who owned more cultivated land produce more crops that improve their life than those owned limited cultivated land because land is a basic resource in rural areas. Different empirical study showed that households who owned more size of cultivated land were better food secured than those limited cultivated land [13].

Table 3. Cultivated land distribution of the households.

\begin{tabular}{|c|c|c|c|c|c|c|}
\hline \multirow{2}{*}{ Cultivated land in hectare } & \multicolumn{2}{|c|}{ Food secure, $N=52$} & \multicolumn{2}{|c|}{ Food insecure, $N=20$} & \multicolumn{2}{|c|}{ Total, $\mathrm{N}=72$} \\
\hline & Number & Percent & Number & Percent & Number & Percent \\
\hline $0.5-5$ he. & 9 & 12.5 & 12 & 16.67 & 21 & 29.17 \\
\hline $6-10$ he & 36 & 50 & 7 & 9.72 & 43 & 59.72 \\
\hline $11-12$ he & 7 & 9.72 & 1 & 1.39 & 8 & 11.11 \\
\hline \multicolumn{7}{|c|}{$\begin{array}{l}\text { Mean: } 7.7211544 .3256 .777778 \\
\text { St.dev: } 2.7339792 .5560813 .076363 \\
\text { t-value }=3.396, \mathrm{P}<0.05\end{array}$} \\
\hline
\end{tabular}

Own computation, 2016/2017 Significant at 5\%

Tropical livestock unit distribution of the households

Tropical livestock production is one of the main economic activities in the study area. A majority of the households surveyed rearing various kinds of animals in order to produce animal products to generate income both contributing to access to their food. The kinds of animals reared in the Gumay woreda include cattle, sheep, goats, donkeys and chicken. Small ruminants and chicken are reared for meat and egg production respectively both for home consumption and for sale. The average numbers of livestock holding between the two groups of sample households differ. In order to make comparison of the animal size between the household groups, the herd size was converted into total livestock units (TLU) based on Stock (appendix 9).
The food secure group has also large average size of total livestock holding when the total LU/AE is considered, that is 3.17 LU/AE as compared to $1.49 \mathrm{LU} / \mathrm{AE}$ for food insecure group. From the total sample households $4.17 \%$ have no livestock owners who all are food in secure, $16.67 \%$ own TLU between $0.12-1.02$ while $6.94 \%$ are food secure and $9.72 \%$ are food in secure, $18.06 \%$ own TLU between 1.039 2.35 while $12.5 \%$ of food secure households and $5.56 \%$ of them are food insecure, $20.83 \%$ own TLU between 2.393.004 while $18.05 \%$ of food secure households and $2.78 \%$ of them are food insecure, $15.28 \%$ own TLU between 3.254.004 where $11.11 \%$ are food secure and $4.17 \%$ are food in secure households, $25 \%$ own between 4.09-5.96 own TLU where $23.61 \%$ are food secure households and $1.39 \%$ are 
food in secure households. The food secure has mean TLU of 3.17 which is larger than the mean of TLU 1.49 of food in secure group. The mean difference between the owners of
TLU food secure and food insecure household at t-value= 6.9 was statistically significance at $5 \%$ probability level (Table 4).

Table 4. Livestock distribution of the households.

\begin{tabular}{|c|c|c|c|c|c|c|}
\hline \multirow{2}{*}{ TLU } & \multicolumn{2}{|c|}{ Food secure, $N=52$} & \multicolumn{2}{|c|}{ Food insecure, $\mathbf{N}=\mathbf{2 0}$} & \multicolumn{2}{|c|}{ Total, $\mathrm{N}=72$} \\
\hline & Number & Percent & Number & Percent & Number & Percent \\
\hline 0 & 0 & 0 & 3 & 4.17 & 3 & 4.17 \\
\hline $0.12-1.02$ & 5 & 6.94 & 7 & 9.72 & 12 & 16.67 \\
\hline $1.039-2.35$ & 9 & 12.5 & 4 & 5.56 & 13 & 18.06 \\
\hline $2.39-3.004$ & 13 & 18.05 & 2 & 2.78 & 15 & 20.83 \\
\hline $3.25-4.004$ & 8 & 11.11 & 3 & 4.17 & 11 & 15.28 \\
\hline $4.09-5.96$ & 17 & 23.61 & 1 & 1.39 & 18 & 25 \\
\hline \multicolumn{7}{|c|}{ Mean: 3.1719231 .495622 .706292} \\
\hline \multicolumn{7}{|c|}{ St. dev: 1.4610121 .5134621 .648605} \\
\hline t.-values $=-$ & & & & & & \\
\hline
\end{tabular}

Own computation, 2016/2017 Significant at 5\%

Fertilizer distribution of the households

From the study area the total of households who used fertilizer was $77.78 \%$ and non- users was $22.22 \%$. Among food secured households, $72.22 \%$, of them where users of fertilizer were $61.11 \%$ and $11.11 \%$ were non-users. Out of $27.78 \%$ food insecure households, $16.67 \%$ of them non fertilizer users and $11.11 \%$ of them were users. The standard deviation difference between the food secure and food insecure households at chi $(2)=0.0029$ was statistically significance at $5 \%$ probability level (Table 5). This shows households who use fertilizer in crop production were more food secured than those of non-users in the study area.

Table 5. Fertilizer distribution of the households.

\begin{tabular}{llllll}
\hline \multirow{2}{*}{ Fertilizer } & \multicolumn{2}{l}{ Food secure N=52 } & \multicolumn{2}{c}{ Food insecure N=20 } & Total N=72 \\
\cline { 2 - 6 } & Number & Percent & Number & Percent & Number \\
\hline Fertilizer users & 44 & 61.11 & 12 & 16.67 & 56 \\
Non- users & 8 & 11.11 & 8 & 11.11 & 16 \\
Total & 52 & 72.22 & 20 & 27.78 & 72 \\
chi $(2)=0.0029 \mathrm{P}<0.05$ & & & & & \\
\hline
\end{tabular}

Own computation, 2016/2017 Significant at 5\%

Improved seed distribution of the households

The total sample households who used improved seeds or high variety yield of maize and wheat were $91.67 \%$ and nonusers were $8.33 \%$. Among food secured households, $69.44 \%$ were users of improved seed and $2.78 \%$ were non-users of improved seeds. From food insecure households, 27.78\%, those did not use improved seeds were $5.56 \%$ and $22.22 \%$ were users of improved seeds. The study showed that the standard deviation difference of improved seed between food secure and food insecure households at chi (2) $=0.0378$ was statistically significance at $5 \%$ probability level (Table 6). This implies improved seed increase the productivity of crops yields which induces the food security status of the households in the study area.

Table 6. Improved seed distribution of the households.

\begin{tabular}{llllll}
\hline \multirow{2}{*}{ Improved seeds } & \multicolumn{2}{l}{ Food secure, $\mathbf{N = 5 2}$} & \multicolumn{2}{l}{ Food insecure, $\mathbf{N}=\mathbf{2 0}$} & Total, N=72 \\
\cline { 2 - 6 } & Number & Percent & Number & Percent & Number \\
\hline Users improved seeds & 50 & 69.44 & 16 & 22.22 & 66 \\
Non-improved seed users & 2 & 2.78 & 4 & 5.56 & 6 \\
Total & 52 & 72.22 & 20 & 27.78 & 72 \\
Chi $(2)=0.0378 \mathrm{P}<0.05$ & & & & & \\
\hline
\end{tabular}

Own computation, 2016/2017 Significant at 5\%

Table 7. The summary statistics of discrete variables.

\begin{tabular}{|c|c|c|c|c|c|c|}
\hline & \multirow{3}{*}{ Variables } & \multicolumn{4}{|c|}{ Food security status of households } & \multirow{3}{*}{ Chi-square $\left(\chi^{2}\right)$} \\
\hline & & \multicolumn{2}{|c|}{ Food secure } & \multicolumn{2}{|c|}{ Food insecure } & \\
\hline & & Mean & St.dev & Mean & St.dev & \\
\hline 1 & Sex & 0.77 & 0.43 & 0.7 & 0.47 & 0.9481 \\
\hline 2 & Fertility & 0.85 & 0.36 & 0.55 & 0.51 & $0.0029 *$ \\
\hline 3 & Improved seed & 0.96 & 0.19 & 0.8 & 0.41 & $0.0378^{*}$ \\
\hline
\end{tabular}

Own computation, $2016 / 2017 *$ statistically significant at 5\% 
Table. 8. The summary statistics of continuous variables.

\begin{tabular}{|c|c|c|c|c|c|c|}
\hline \multirow{3}{*}{ No } & \multirow{3}{*}{ Variables } & \multicolumn{4}{|c|}{ Food security status of households } & \multirow{3}{*}{ Test statistic (t) } \\
\hline & & \multicolumn{2}{|c|}{ Food secure } & \multicolumn{2}{|c|}{ Food insecure } & \\
\hline & & Mean & St.dev & Mean & St.dev & \\
\hline 1 & Age & 44.25 & 8.62 & 51.15 & 11.59 & $6.93 *$ \\
\hline 2 & Family size & 5.10 & 1.9 & 5.6 & 2.50 & 1.08 \\
\hline 3 & Education & 7.42 & 2.03 & 6.95 & 2.89 & 0.38 \\
\hline 4 & Cultivated land & 7.72 & 2.73 & 4.33 & 2.56 & $8.80 *$ \\
\hline 5 & Income & 20786.54 & 10158.88 & 18,005 & $6,220.127$ & 2.25 \\
\hline 6 & Tropical livestock unit & 3.17 & 1.46 & 1.50 & 1.51 & $7.54 *$ \\
\hline
\end{tabular}

Own computation, 2016/2017* statistically significant at 5\%

Summary statistics of explanatory variables Table 8 above provide the summary of means and standard deviations of the farmer scores on the two groups on hypothesized continuous and discrete variables. Accordingly, t-tests and chi-square tests were used to substantiate the presence or absence of differences between the two groups' poor and non-poor households and the value for each variable were presented in the respectively.

\subsection{Econometrics Results}

In this study application of econometrics analysis includes test of goodness-of-fit of the model, test of, variance inflation factor, contingency coefficient, odds ratio, t-test and chi (2) test.

Goodness- of- fit of the model

In this study Hosmer and Lemeshow test is used to test the fitness of the binary logistic model to fit the gathered data. As shown in Table 9 Hosmer and Lemeshow test indicated the significance level of 0.0665 which is above 0.05 . Due to this; the model is good enough to analyze the accepted data and estimates the coefficient of independent variables.

Multicollinearity

Before fitting the models, the existences of serious problem of multicollinearity among the hypothesized explanatory variables were checked using variance inflation factor and contingency coefficient.

The values of variance inflation factor (Vif) for each of the continuous variables for this study were less than 10 . This implies, there was no a multicollinearity problem among all the hypothesized continuous variables included in the model [4]. But in this study the average Vif is 1.13 that is less than 10 therefore; there is no serious multicollinearity problem (appendix 3). As a result, 6 explanatory continuous variables were entered into binary logistic model for analysis.

The result of contingency coefficients $(\mathrm{Cc})$ revealed that there was no a serious problem of association among discrete explanatory variables as the contingency coefficients did not exceed 0.75. Therefore, all the hypothesized dummy variables were included in the logistic regression model [4]. Accordingly, the results of the computation reveal that there was no serious problem of association among discrete explanatory variables. Hence, all the 3 discrete variables were entered into binary logistic model for analysis.

Hetroskedasticity

Heteroscedasticity means a situation in which the variance of the dependent variable varies across the data. Many methods in regression analysis are based on the assumption of homoscedasticity or equal (homo) spread (scedasticity), that is, equal variance [4]. In logit analysis there is no equal variance or homogeneity of variance assumptions and the variance of the error terms is not constant. In this analysis, Cook Weisberg test for heteroscedasticity (hettest) using fitted values of food security is carried out in Stata 12 software. The result of Chi-square $\mathrm{x}^{2}(1)=0.83$ Prob $>\mathrm{chi}^{2}=$ 0.3632 . Thus reject the null hypothesis which says there is constant variance and therefore, conclude that the dependent variable varies across the data (appendix 5).

Table 9. Logistic regression model result.

\begin{tabular}{lllll}
\hline Food secure & Coefficient & Standard error & Z & Odds ratio \\
\hline Sex & .26 & .959 & 0.27 & 1.29 \\
Age & $.16^{*}$ & .052 & -2.02 & .900 \\
Family size & -.07 & .255 & -0.26 & .937 \\
Education & .16 & .204 & 0.81 & 1.18 \\
Cultivated land & $.36^{*}$ & .169 & 2.16 & 1.44 \\
Improved seed & $3.46^{*}$ & 1.65 & 2.10 & 31.85 \\
Fertilizer & $2.74^{*}$ & 1.25 & 2.18 & 15.56 \\
Income & .00 & .000 & 0.66 & 1.00 \\
Tlu & $1.02^{*}$ & .418 & 2.44 & -1.55 \\
Constant & -5.69 & 3.675 & -003 & \\
\hline
\end{tabular}

Model result, $2017 *$ statistically significant at 5\%

Age of the households (age): Age of household is positively correlated with food security as hypothesized prior and statistically significant at $5 \%$ probability level to influence the food status of farmer in the study area. As shown in Table 9, the odds ratio 0.90 indicate that other things remain constant, the probability of a farmer food 
security increased by a factor of 0.90 as age of household increased by one year. As age of household increased, they got more experience in crops production that increase agricultural production and accumulated more assets that improve their food security status than younger households.

Cultivated land (cult land): Cultivated land is positively correlated with food security as hypothesized prior and statistically significant at $5 \%$ probability level to influence the food status of household in the study area. As shown in Table 9, the odds ratio 1.44 indicate that, other things remain constant, the probability of households in favor of being food secure increased by a factor of 1.44 as areas of cultivated land increased by one hectare. This implies households who owned relatively more cultivated land can produce more crops that improve their food security status and living standards than those of less cultivated land owners. Food insecure households with less cultivated land, practice share cropping system where they give more ratios to land owners and receives less ratios for themselves which keep them in status of food insecurity in the study area. The study confirms with the empirical findings of [1], food security and cultivated land is positively correlated.

Improved seed (improvseed): Improved seed is positively correlated with food security as hypothesized prior in the study area. The odds ratio result shows in Table 9 that, the probability of improved seed user household to be food secure was 31.85 times more than the probability of improved seed non user. This implies improved seed such as high variety of seed; maize and wheat have high potential to increase farmer productivity and enhance food security in the study area. The study confirms with [13] empirical finding, improved seed provision increases household's food security.

Fertilizer (fertilizer): Fertilizer is positively correlated with food security as expected prior. Thus, there is a strong ground to support the hypothesis that fertilizer usage increases the probability of being food secure. The odds ratio result shows in Table 9 that, the probability of fertilizer user household to be food secure were 15.56 times more than the probability of non-fertilizer user. Fertilizer use, thus, increases the possibility of income diversification which all enables households to have access and there by fulfilling their basic necessities. This empirical study supports with other authors' empirical findings, [14], fertilizer and food security positively correlated.

Tropical Livestock Unit (Tlu): - Furthermore, higher livestock size has a positive and significant effect on food security. This result could be due to the fact that livestock is used in times of production shortfalls as safety nets and households may sell a part of it to purchase inputs, such as fertilizers and pesticides. On the other hand, households with more livestock produce more milk, milk products and meat for direct consumption and owners could be more food secured. This enables the households to have better chance to earn more income from livestock production which enables them by increasing purchasing power of food during food shortage and could invest in purchasing of farm inputs that increase food production, and able in ensuring household food security. The odds ratio result shows in Table 9 that, the probability of household to be food secure was 2.77 times increases as the total livestock unit increased by one TLU. The empirical finding, [5], tropical livestock unit and food security positively correlated.

\section{Summary, Conclusion and Recommendation}

\subsection{Conclusion and Summary}

This study was conducted in Jimma zone of Oromia regional state particularly in GumayWoreda. It is one of the areas where the problems of household food security prevail. A total of 72 sample households were selected that intend to represent the all households in the woreda, multi-stage sampling was employed to select farmer from each kebeles. First, Gumay woreda was selected for purposive sampling. Second, stratified sampling was employed to categorize households into three strata based on types of crops they produce and 72 sample sizes of farmers allocated to these three strata and to each kebeles in a given strata based on proportionate stratified sampling. Third, representatives of farmers in each kebeles selected through employing systematic sampling and the first farmer was selected by lottery method and the rest were selected by interval.

To gather data on factors affecting household's food security in Gumay woreda, structured questionnaires were prepared in Afan Oromo and then posed to households. The structured questionnaires contain information about the demographic and socio-economic characteristics of the farmer such as sex, age, family size and education, size of cultivated land, fertilizer, improved seed, income and tropical livestock unit. Based on experience and education, 8 enumerators were selected to collect data from respondents.

The data collected were presented, organized and discussed using descriptive statistics and logistic econometric model analyses. In the first stage, attempts were made to explore data and information pertaining to the general set of sample farmers and the raw data were organized and discussed using means, percentage, and standard deviations. The t-statistics and chi-square $\left(\chi^{2}\right)$ tests of significance were employed, respectively, for screening continuous and discrete potential candidate variables capable of differentiating food secure from food insecure farmers. The result shows food secure farmers differ appreciably with 3 continuous variables out of 6 hypothesized and with 2 out of 3 discrete variables at less than $5 \%$ probability level. Thus, the analysis of the survey data was carried out for the intended purpose.

To categorize farmers into food secure and insecure in the study area, a minimum expenditure requirement 4,200 birr per AE was set as a bench mark cut of point. Based on this out of all sample farmers of the study area 52 farmers or $72.22 \%$ were food secured and 20 farmers $22.78 \%$ food insecure.

To identify the continuous and discrete potential candidate variables capable of affecting the food security status in the 
study area, logistic regression model was used. The model results reveal that among 9 explanatory variables included in the logistic model, 5 were found to be significant at less than $5 \%$ probability level in the study area. Additionally, the result of the study shows that age of the households, fertilizer, cultivated land, improved seed, and livestock unit are positively correlated and statistically significant at $5 \%$ probability level to influence the status of household food security in the study area.

\subsection{Recommendation}

The study showed that age of farmer, cultivated land, fertilizer, improved seed, and tropical livestock unit positively influences farmer food security. These factors highly differentiate food status of among households in the study area. So, in order to solve the food insecurity problems in the study area, the following policy implications are recommended.

Age of the farmer has a positive impact on food security. This implies in the study area, the older households a more food secure than younger households. Therefore, the government and stakeholders should arrange special trainings for younger households on topics such as saving, farm management, where the youth are lacking experience.

Cultivated land size owned by households was found to be significantly influence farmer food security; as cultivable land size is limited it is important to reduce number of households who depend on limited cultivated land by introducing agro-industries and other non-farm job opportunities into rural areas. Intensive agricultural practices should also be intensively promoted to enhance productivity on the limited land available.

Fertilizer is found to be positively and statistically significant to determine food security of households in the study area. The finding showed that majority of the households who apply fertilizer on their crop production get more output and food secured than those of non-users and who are relatively more food insecure. The government and stakeholders should train non fertilizer user about the contribution of fertilizer in crop productivity where they lacking awareness.

Improved seed is positively and statistically significant influencing household's food security in the study area. Majority of households who apply improved seed get maximum agricultural output and more food secured than those of non-users who are majority of them are food insecure. To solve this problem, the government and concerned party should train non fertilizer user farmers on the crop productivity of improved seed over the dominant ones. The government should work hard solve on fertilizer user households' problems (supply side and demand side) in getting improved seed on time.

Findings of this study showed that livestock have positive and statistically significant to influence the household's food security. This implies majority of households with large livestock are more food secured than those of less owned who is relatively more food insecure. To solve this problem the government and stakeholders should provide better use of improved breeding livestock for food insecure who are less owned.

\section{Authors' Contributions}

The authors worked jointly to come up with the paper. The authors read and approved the final manuscript.

\section{Availability of Data}

All the data, employed in this study, are available via contacting and requesting the corresponding, observation and also the secondary data sources like: Reading articles, news, the historian materials.

\section{Acknowledgements}

First of all, we would like to thank the God. Then we also, would like to thank the large number of individuals and institution Ethiopian Biodiversity Institute staff that have contributed to construct and advise us.

\section{References}

[1] Abebaw (2003). Dimensions and Determinants of Food Security among Rural Household in Dire Dawa; Eastern Ethiopia. A M.Sc. Thesis of Graduate Studies of Alemaya. University, Alemaya.

[2] Ayalne (2002) Land Degradation. Impoverishment and Livelihood Strategies of Rural Households in Ethiopia: Farmers Perceptions and Policy implication. Vol. 8 Shaker Verlag, Germany.

[3] AFI Alliance for Financial Inclusion (2012) The AFI registers. http://www.afi-global.org.

[4] Berhanu (2001) Food insecurity in Ethiopia. The impact of socio-political forces. Development Research Series Working Paper No. 102, DIR \& Institute for History, International and Social Studies, Aalborg University, Denmark.

[5] Bogale and Shimels (2009) Household level determinants of food insecurity in rural areas of Dire Dawa, Eastern Ethiopia. Afr. J. Food Agric. Nutr. Dev., 9: 1914-1926.

[6] Clay (et al) (1999) Food aid. Food aid has been used to enhance the level of food supplies and protect the income of victims of drought and famine.

[7] FAO the State of Food and Agriculture (2019) Moving forward on food loss and waste reduction. Rome. Licence: CC BY-NC-SA 3.0.

[8] FAO the State of Food and Agriculture (2017) reported that the prevalence of hunger was on the rise in Africa, after many years of decline. The FAO registers. http://www.fao.org.

[9] FAO the State of Food and Agriculture (2018) disaster risk reduction must be aligned as well as coordinated with interventions in nutrition and food systems across sectors. The FAO registers. http://www.fao.org. 
[10] FAO the State of Food and Agriculture (2010) the Ethiopian population lives below the poverty line and more than 31 million people are undernourished. The FAO registers. http://www.fao.org.

[11] Gujarati (2004) Basic Econometrics, $4^{\text {th }}$ ed. McGraw-Hill, New York.

[12] Gebre (2012) Determinants of food insecurity among households in Addis Ababa city, Ethiopia. Interdiscipl. Descript. Complex Syst., 10: 159-173.

[13] Mulugeta (2002) Determinants of Household Food Security in
Eastern Oromia, Ethiopia: The Case of Boke District of Western Hararghe Zone. M.Sc. Thesis of Graduate Studies of Alemaya University.

[14] Solomon (2011) empirical finding, improved seed provision increases household's food security. Contribution of moringa (Moringa stenopetala, Bac.), a highly nutritious vegetable tree for food security in south Ethiopia: a review.

[15] Tefera (etal) (2011) food insecurity had negative impact on educational attainment of adolescents. The food insecurity gap and severity were 16.83 and 6.9 percent respectively. Ideas.repec.org. 